\title{
Psoriatic arthritis and sacroiliitis are associated with increased vascular inflammation by 18-fluorodeoxyglucose positron emission tomography computed tomography: baseline report from the Psoriasis Atherosclerosis and Cardiometabolic Disease Initiative
}

Shawn Rose ${ }^{1,2}$, Jenny Dave ${ }^{1}$, Corina Millo ${ }^{3}$, Haley B Naik ${ }^{4}$, Evan L Siegel ${ }^{5}$ and Nehal N Mehta ${ }^{1 *}$

\begin{abstract}
Introduction: Psoriasis and psoriatic arthritis (PsA) increase cardiovascular disease (CVD) risk, but surrogate markers for CVD in these disorders are inadequate. Because the presence of sacroiliitis may portend more severe PsA, we hypothesized that sacroiliitis defined by computed tomography (CT) would be associated with increased vascular inflammation defined by 18-fluorodeoxyglucose-positron emission tomography/computed tomography (FDG-PET/CT), which is an established measure of CVD.

Methods: Participants $(n=65)$ underwent whole-body FDG-PET/CT. Metabolic activity of the aorta was measured using the maximal standardized uptake value $\left(S U V_{\max }\right)$, a measure of atherosclerotic plaque activity. The primary outcome was aortic vascular inflammation. Linear regression (with $\beta$-coefficients ( $\beta$ ) and $P$-values reported for PsA and sacroiliitis) was used to adjust for CVD risk factors to determine associations of PsA or sacroiliitis with vascular inflammation. Likelihood ratio testing was performed to evaluate the contribution of sacroiliitis to vascular disease estimation compared to the effects of PSA and traditional CVD risk factors.

Results: Vascular inflammation (measured as SUV $V_{\text {max }}$ ) was greater $(P<0.001)$ in patients with sacroiliitis (mean $\pm \mathrm{SD}=$ $7.33 \pm 2.09)$ defined by $C T$ compared to those without sacroiliitis $(6.39 \pm 1.49, P=0.038)$. There were associations between PsA and aortic inflammation $(\beta=0.124, P<0.001)$ and between sacroiliitis and aortic inflammation $(\beta=0.270$, $P<0.001)$ after adjusting for CVD risk factors. Sacroiliitis predicted vascular inflammation beyond PsA and CVD risk factors $\left(X^{2}=124.6, P<0.001\right)$.

Conclusions: Sacroiliitis is associated with increased vascular inflammation detected by FDG-PET/CT, suggesting that sacroiliac joint disease may identify patients at greater risk for CVD. Large, ongoing prospective studies are required to confirm these findings.
\end{abstract}

\footnotetext{
* Correspondence: nehal.mehta@nih.gov

'Section of Inflammation and Cardiometabolic Diseases, National Heart,

Lung, and Blood Institute (NHLBI), National Institutes of Health, Bethesda, MD

20892, USA

Full list of author information is available at the end of the article
} 


\section{Introduction}

Systemic inflammatory disorders, including psoriasis (Pso) [1-3] and psoriatic arthritis (PsA) [3], increase incident cardiovascular events beyond traditional cardiovascular disease (CVD) risk factors [4]. Understanding of this elevated risk has been hampered by the lack of suitable clinical biomarkers linking systemic inflammation and CVD. Prevention of increased CVD morbidity and mortality in Pso and PsA requires identification of those patients at greatest risk for these diseases prior to the development of overt symptoms. 18-Fluorodeoxyglucose-positron emission tomography/computed tomography (FDG-PET/CT) is an imaging modality that may provide this capability, as it delineates enhanced metabolic activity in tissues in vivo, including vascular inflammation [5-9]. Importantly, vascular inflammation seen on FDG-PET/CT scans has been shown to precede the development of atherosclerotic disease [10] and to predict future cardiovascular events $[11,12]$. Our prior investigations in which we utilized FDGPET/CT have shown increased inflammation in multiple tissues, including the skin, liver, joints, entheses and vasculature in Pso and PsA patients compared to healthy controls $[6,13,14]$. We have also previously demonstrated relationships between FDG-PET/CT imaging measurements and both known and novel CVD biomarkers, thereby validating FDG-PET/CT findings as reliable predictors of outcome [15]. However, these pilot studies were underpowered to adequately assess for PsA or axial disease.

Sacroiliitis is a characteristic feature of the spondyloarthropathies, including PsA [16]. Imaging of patients with sacroiliitis is an element of the current classification criteria for these disorders $[17,18]$. Imaging of the sacroiliac (SI) joints by CT scan is one modality that is accepted for making the diagnosis of sacroiliitis [19-27]. Further, the presence of sacroiliitis may identify a PsA subgroup at risk for more severe arthropathy $[28,29]$. Greater inflammatory burden imposed by severe Pso $[1,30,31]$ and the presence of PsA [32,33] increases the risk of CVD. Thus, we hypothesized that PsA and sacroiliitis diagnosed by CT scan would be associated with increased vascular inflammation by FDG-PET/CT scan in a wellcharacterized population of Pso patients with versus without a diagnosis of PsA. Here we present a consecutive sample of 65 patients who completed baseline studies in the Psoriasis Atherosclerosis and Cardiometabolic Disease Initiative (PACI; ClinicalTrials.gov Identifier: NCT01778569). A major aim of this prospective, longitudinal study is to identify incident biomarkers of vascular and metabolic disease in Pso and PsA.

\section{Methods}

\section{Study population}

Whole-body FDG-PET/CT was performed in a consecutive sample of patients $(n=65)$ ages 18 to 70 years with
Pso alone $(n=38)$ or with both Pso and PsA $(n=27)$. Our study population was recruited to the National Institutes of Health (NIH) Clinical Center using flyers and pamphlets distributed at dermatology clinics and via academic dermatological societies, as well as by using web-driven tools such as [34] and [35]. Diagnostic confirmation of plaque Pso and assessment of body surface area (BSA) and Psoriasis Area and Severity Index (PASI) were performed by a dermatologist. PsA classifications were confirmed by a rheumatologist according to the ClASsification criteria for Psoriatic ARthritis (CASPAR) [36]. A rheumatologist did the swollen and tender joint counts using the American College of Rheumatology 66/ 68 joint count core set [37]. Clinical assessment of enthesitis (by Leeds Enthesitis Index score [38]), dactylitis (by number of dactylitic digits) and inflammatory back pain (according to Assessment of SpondyloArthritis international Society (ASAS) criteria [39] and Calin criteria [40]) was also performed by a rheumatologist. Exclusion criteria included disease states that can increase systemic or vascular inflammation, such as known history of CVD, uncontrolled hypertension (defined as systolic blood pressure (SBP) $>180 \mathrm{mmHg}$ or diastolic blood pressure (DBP) $>95 \mathrm{mmHg}$ ), nondermatologic malignant disease within the past 5 years, positive HIV status, major surgery within the past 3 months and history of intravenous drug use or active infection within the preceding 72 hours. Hypertension was defined as SBP $>140 \mathrm{mmHg}$, DBP $>90 \mathrm{mmHg}$ and/or currently on antihypertensive therapy. Hyperlipidemia was defined as total cholesterol $>200 \mathrm{mg} / \mathrm{dl}$, low-density lipoprotein (LDL) $\geq 160 \mathrm{mg} / \mathrm{dl}$, high-density lipoprotein (HDL) $<40 \mathrm{mg} / \mathrm{dl}$, triglycerides $>150 \mathrm{mg} / \mathrm{dl}$ and/or use of a cholesterol-lowering agent. Diabetes was defined as fasting glucose $\geq 126 \mathrm{mg} / \mathrm{dl}$, hemoglobin A1c $\geq 6.5 \%$ and/or taking antidiabetic therapy.

\section{FDG-PET/CT}

Whole-body FDG-PET/CT scans were obtained using a standardized published protocol [13]. Following an overnight fast, patients were imaged 60 minutes after receiving an injection of $370 \mathrm{MBq}$ of 18-FDG. Images were acquired in three-dimensional mode using a Siemens Biograph TruePoint PET/CT scanner (Siemens Healthcare, Erlangen, Germany). FDG-PET/CT images were reviewed by a reader, blinded to all patient characteristics, using dedicated PET/CT image analysis software (Extended Brilliance Workstation (EBW); Philips Healthcare, Amsterdam, the Netherlands). FDG uptake in the thoracic and abdominal aorta was quantified using published methods [6]. Briefly, circular two-dimensional regions of interest (ROI) circumscribing the external aortic contour were drawn on serial contiguous transaxial 4$\mathrm{mm}$ sections from the level of the aortic root to the iliac bifurcation (Figure 1). Each axial segment provided two 


\section{PROXIMAL AORTA}

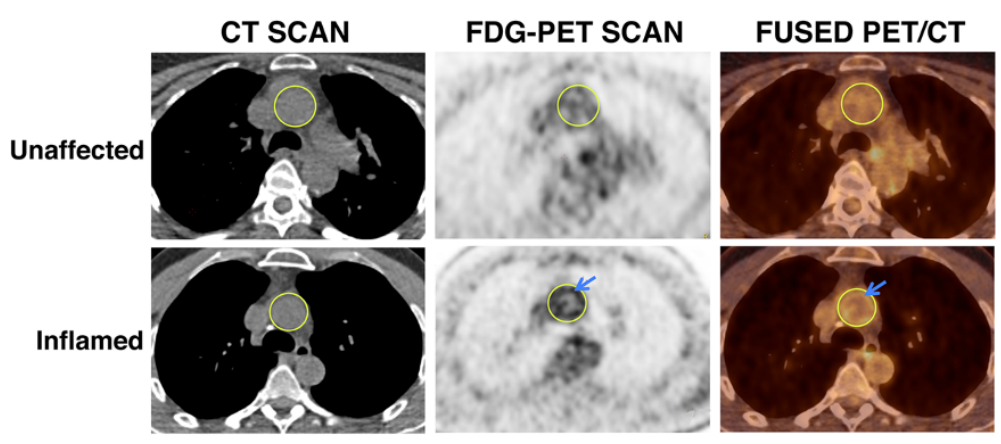

Figure 1 18-fluorodeoxyglucose-positron emission tomography/computed tomography delineates vascular inflammation. Images shown are representative computed tomography (CT) (left panels), 18-fluorodeoxyglucose-positron emission tomography (FDG-PET) (center panels) and fused FDG-PET/CT transaxial (right panels) scans from a patient with an unaffected aortic vasculature (upper panel) and one with an inflamed aortic vasculature (lower panel). Regions of interest outlining the ascending thoracic aorta are depicted in yellow in all images. A ring-shaped focus of increased metabolic activity in the aortic wall is also shown (blue arrows in FDG/PET and fused FDG-PET/CT images).

measures of tissue metabolic uptake [6]: mean and maximum standardized uptake $\left(\mathrm{SUV}_{\text {mean }}\right.$ and $\mathrm{SUV}_{\max }$, respectively). $\mathrm{SUV}_{\text {mean }}$ and $\mathrm{SUV}_{\max }$ values were determined using commercial software (EBW) for each successive slice. $\mathrm{SUV}_{\max }$ values were averaged over three consecutive slices to measure the most inflamed aortic region in each patient. A nuclear medicine specialist independently evaluated FDG-PET/CT scans for imaging quality, radiotracer biodistribution, uptake time and clinical findings.

\section{Imaging evaluation for sacroiliitis}

Sacroiliitis diagnosed by CT scan was evaluated using guidelines developed by Geijer and colleagues [41]. Sacroiliitis grade was classified as "no disease" (that is, radiographically normal, degenerative change evident or some blurring of the joint margins), "suspected disease" (that is, unilateral sclerosis with some erosion) or "definite disease" (that is, bilateral sclerosis with erosion, or unilateral or bilateral sclerosis with severe erosion and a change in joint space with or without partial ankylosis, or complete ankylosis). Both axial and coronal CT scan orientations were examined. Sclerosis, erosions, ankylosis and/or joint space changes had to be evident on at least two consecutive slices to be deemed significant.

\section{Serum factor determination}

Fasting levels of total, HDL and LDL cholesterol, triglycerides, glucose, erythrocyte sedimentation rate (ESR) and high-sensitivity C-reactive protein (hsCRP) were measured in a clinical laboratory.

\section{Statistical analysis}

Normality was assessed by skewness and kurtosis. Normally distributed continuous variables were compared using Student's $t$-test. Continuous variables lacking a normal distribution were compared using Mann-Whitney $U$ test. Dichotomous variable comparisons were performed using Fisher's exact test. Student's $t$-test was employed to compare FDG-PET/CT measures $\left(\mathrm{SUV}_{\max }\right)$ of aortic inflammation between Pso and PsA groups and between patients with or without CT evidence of sacroiliitis. Only those patients with definitive disease defined by CT were considered to have sacroiliitis for all analyses. Patients not meeting the CASPAR criteria [36] for PsA were classified as having PSO. Relationships between variables were determined using Spearman correlation analysis and are reported as Spearman $\rho(r)$ values. Multivariate linear regression analysis was performed using aortic $\mathrm{SUV}_{\max }$ as the dependent variable and CVD risk factors (age, sex, body mass index (BMI), diabetes, hypertension, dyslipidemia and pack-years of tobacco use) and either PsA or sacroiliitis evident by CT scan as independent variables, as reported. Sex, diabetes, hypertension, dyslipidemia, PsA and sacroiliitis were adjusted for as dichotomous variables in the models; all other variables were continuous. Similar findings were revealed in independent analyses designating sex, PsA and sacroiliitis as dichotomous variables and age, BMI, fasting glucose, SBP, LDL cholesterol, tobacco use and aortic $\mathrm{SUV}_{\max }$ as continuous variables. Both fixed- and random-effects regression analyses were performed on each model to accommodate within-patient correlation of $S_{U V} V_{\max }$ values [13]. Because the magnitude of the estimates of PsA and sacroiliitis using vascular measures did not differ when fixed- and random-effects regression analyses were performed, we report $\beta$-coefficients $(\beta)$ and $P$-values for the fixed effects models after adjustment for CVD risk factors. Further, we examined the outcome variable aortic $\mathrm{SUV}_{\max }$ in separate multivariate linear regression models using either slice-by-slice $\mathrm{SUV}_{\max }$ measures or collapsed individual patient values. The magnitude of the effect of the covariates on aortic $\mathrm{SUV}_{\text {max }}$ was similar in both models; hence, we report the slice-by-slice 
data. On the basis of prior published results [5] demonstrating that aortic SUV increased 0.1 U (SD \pm 0.1$)$ per decade of life, we considered this to be a clinically relevant difference. Therefore, with these assumptions, our sample size $(n=65)$ provided $>90 \%$ power to detect a difference of 0.1 in aortic vascular inflammation by the presence or absence of SI inflammation. Likelihood-ratio testing was performed in nested Tobit models to determine the incremental value of sacroiliitis to CVD estimation above and beyond PsA and traditional CVD risk factors. STATA 12 statistical software (StataCorp, College Station, TX, USA) was utilized for all analyses. Study approval was obtained from the National Heart, Lung, and Blood Institute Institutional Review Board in accordance with the Declaration of Helsinki. All guidelines for GCP and those set forth by the NIH Radiation Safety Commission and in the Belmont Report (National Commission for the Protection of $\mathrm{Hu}$ man Subjects of Biomedical and Behavioral Research) were followed. All study participants provided written informed consent.

\section{Results \\ Patient demographics, disease assessments and CVD risk factors}

Patient characteristics $(n=65)$ and laboratory measurements are presented in Table 1 for the whole sample and for the Pso $(n=38)$ and PsA $(n=27)$ subgroups. Our study population had a median age of 53 years, was nearly equally distributed by sex (54\% male) and had moderate skin disease on average (mean BSA $=9.2$, mean PASI score $=7.8$ ) (Table 1$)$. The proportion who had PsA was $41 \%$. Median skin disease duration was 20 years for both the Pso and PsA subgroups, and the median duration of joint disease was 10 years in PsA patients (Table 1). One patient met both the Calin and ASAS criteria for inflammatory back pain. This patient was classified as having Pso, however, due to not meeting the CASPAR criteria for PsA and having CT images showing advanced degenerative and postsurgical changes in the spine without evidence of spondylitis or sacroiliitis. Two additional patients were definitively diagnosed with sacroiliitis by CT without evidence of inflammatory back pain, SI tenderness to palpation or provocative maneuvers, arthritis, enthesitis or dactylitis. Because both of those two patients met the CASPAR criteria for PsA, they were classified as having asymptomatic axial PsA. Sacroiliitis diagnosed by CT scan was confirmed in $44 \%$ of PsA patients (Table 1).

We also assessed Medication use and cardiovascular and metabolic comorbidities in our study population (Table 1). Many patients (37\%) were using topical steroids, whereas systemic steroid therapy and phototherapy were rare (Table 1). Disease-modifying antirheumatic drug (DMARD) treatment was uncommon and was not statistically different $(P=0.224)$ between the PsA $(15 \%)$ and Pso (5\%) groups (Table 1). Biologic therapy was more common $(P=0.022)$ in PsA patients $(56 \%)$ than in Pso patients (26\%). Traditional CVD risk factors, including hypertension, dyslipidemia, diabetes mellitus and tobacco use, were prevalent in our study population, as was treatment for these disorders. Presence and treatment of CVD risk factors were not statistically different between the Pso and PsA subgroups (Table 1).

\section{Vascular inflammation measured by FDG-PET/CT is greater in patients with sacroiliitis defined by $\mathrm{CT}$}

We utilized FDG-PET/CT to examine vascular inflammation, as defined by aortic $\mathrm{SUV}_{\text {max }}$, in our study population. Mean (SD) $\mathrm{SUV}_{\max }$ values for the aortic region demonstrating the highest vascular inflammation in three contiguous slices were numerically, but not statistically, greater $(P=0.536)$ in PsA patients $(6.72 \pm 1.92)$ compared to Pso patients $(6.46 \pm 1.43)$ (Table 2). Because sacroiliitis has been shown to signify worse arthropathy in PsA [28,29], we hypothesized that the greater inflammatory state in patients with sacroiliitis may lead to increased vascular inflammation visualized by FDG-PET/CT. Indeed, mean aortic $\mathrm{SUV}_{\max }$ measures (Table 2$)$ were significantly greater $(P=0.038)$ in patients with CT evidence of sacroiliitis $(7.33 \pm 2.09)$ compared to those without SI joint disease (6.39 \pm 1.49$)$. Further, aortic vascular inflammation was greatest in those demonstrating the highest grade (definitive disease) of sacroiliitis by CT scan (Additional file 1: Table S1).

\section{Sacroiliitis defined by CT scan correlates with vascular inflammation evaluated by FDG-PET/CT above and beyond CVD risk factors}

To determine covariates of vascular inflammation by highest atherosclerotic plaque activity within our cohort, individual Spearman correlation analyses were performed between aortic $\mathrm{SUV}_{\max }$ and clinical, laboratory and imaging parameters in the total population and in the Pso and PsA subgroups (Additional file 2: Table S2). In unadjusted analyses of the total study population (Additional file 2: Table S2), aortic $\mathrm{SUV}_{\max }$ was significantly related to traditional CVD risk factors, including age $(r=0.406, P<$ $0.001)$, sex $(r=0.146, P<0.001)$, BMI $(r=0.507, P<$ $0.001)$, hypertension $(r=0.204, P<0.001)$, diabetes $(r=$ 0.186, $P<0.001)$, dyslipidemia $(r=0.226, P<0.001)$ and tobacco use $(r=-0.021, P=0.01)$. Sacroiliitis $(r=0.213$, $P<0.001)$ was more strongly related to vascular inflammation than were the relationships between vascular inflammation and psoriatic arthritis $(r=0.033, P<0.001)$, PASI score $(r=0.001, P=0.919)$, ESR $(r=0.061, P<$ $0.001)$ or hsCRP $(r=-0.005, P=0.513)$ in the total sample. In general, aortic $\mathrm{SUV}_{\max }$ and CVD risk factors were more strongly related in PsA than in Pso patients 
Table 1 Patient characteristics ${ }^{\mathrm{a}}$

\begin{tabular}{|c|c|c|c|c|}
\hline Characteristics & All $(n=65)$ & Pso $(n=38)$ & PsA $(n=27)$ & $P$-value \\
\hline Age, yr & $53(41$ to 61$)$ & 54 (41 to 65$)$ & $52(41$ to 59$)$ & 0.526 \\
\hline Males, $n(\%)$ & $35(54)$ & $21(55)$ & $14(52)$ & 0.806 \\
\hline Psoriasis disease duration, yr & 20 (9 to 32$)$ & 20 (8 to 35$)$ & 20 (10 to 31$)$ & 0.931 \\
\hline Body surface area score, mean (SD) & $9.2(16)$ & $8.1(13.7)$ & $10.8(19.0)$ & 0.827 \\
\hline PASI score, mean (SD) & $7.8(9.3)$ & $7.3(7.9)$ & $8.7(11.2)$ & 0.967 \\
\hline Psoriatic arthritis, $\boldsymbol{n}(\%)$ & $27(41)$ & - & - & - \\
\hline Psoriatic arthritis disease duration, yr & - & - & $10(4$ to 15.5$)$ & - \\
\hline Tender joint count (0 to 68 ), mean (SD) & - & - & $8.9(10.8)$ & - \\
\hline Swollen joint count (0 to 66 ), mean (SD) & - & - & $5.4(9.0)$ & - \\
\hline ASAS inflammatory back pain criteria met, $n(\%)$ & - & - & $4(17)$ & - \\
\hline Calin inflammatory back pain criteria met, $n(\%)$ & - & - & $5(21)$ & - \\
\hline Enthesitis score (0 to 6$)$, mean (SD) & - & - & $1.0(1.5)$ & - \\
\hline Dactylitis count (0 to 20), mean (SD) & - & - & $1.4(3.8)$ & - \\
\hline Sacroiliac disease diagnosed by CT, $n$ (\%) & - & - & $12(44)$ & - \\
\hline DMARD therapy, $n$ (\%) & $6(9)$ & $2(5)$ & $4(15)$ & 0.224 \\
\hline Biologic therapy, $n(\%)$ & $25(39)$ & $10(26)$ & $15(56)$ & 0.022 \\
\hline DMARD and biologic therapy, $n$ (\%) & $4(6)$ & $2(5)$ & $2(7)$ & 1.000 \\
\hline NSAID therapy, $n(\%)$ & $15(23)$ & $3(8)$ & $12(44)$ & 0.001 \\
\hline Phototherapy, $n$ (\%) & $3(5)$ & $1(3)$ & $2(7)$ & 0.565 \\
\hline Topical steroid therapy, $n$ (\%) & $24(37)$ & $14(37)$ & $10(37)$ & 1.000 \\
\hline Systemic steroid therapy, $n(\%)$ & $1(2)$ & $0(0)$ & $1(4)$ & 0.415 \\
\hline Diabetes mellitus, $n$ (\%) & $7(11)$ & $4(11)$ & $3(11)$ & 1.000 \\
\hline Hypertension, $n$ (\%) & $21(32)$ & $13(34)$ & $8(30)$ & 0.791 \\
\hline Dyslipidemia, $n$ (\%) & $44(68)$ & $29(76)$ & $15(56)$ & 0.108 \\
\hline Current tobacco use, $n$ (\%) & $6(9)$ & $3(8)$ & $3(11)$ & 1.000 \\
\hline Former tobacco use, $n(\%)$ & $18(28)$ & $12(32)$ & $6(22)$ & 0.684 \\
\hline Pack-years tobacco use & 0 (0 to 4.5$)$ & $0(0$ to 5$)$ & $0(0$ to 0.8$)$ & 0.590 \\
\hline Diabetes mellitus therapy, $n(\%)$ & $4(6)$ & $2(5)$ & $2(7)$ & 1.000 \\
\hline Antihypertensive therapy, $n$ (\%) & $12(19)$ & $7(18)$ & $5(19)$ & 1.000 \\
\hline Hyperlipidemia therapy, $n$ (\%) & $24(37)$ & $15(39)$ & $9(33)$ & 0.795 \\
\hline Body mass index, $\mathrm{kg} / \mathrm{m}^{2}$ & 29 (25.9 to 32.3$)$ & 29 (24.9 to 32.4$)$ & 29 (26.7 to 32) & 0.572 \\
\hline Systolic blood pressure, $\mathrm{mmHg}$ & 125 (116 to 135$)$ & 129 (120 to 135$)$ & $122(115$ to 133$)$ & 0.266 \\
\hline Diastolic blood pressure, $\mathrm{mmHg}$ & 72 (65 to 78$)$ & 71 (66 to 78$)$ & 74 (63 to 79$)$ & 0.719 \\
\hline Fasting blood glucose, mg/dl & 94 (89 to 104) & $94(89$ to 104$)$ & 94 (89 to 107$)$ & 0.895 \\
\hline Total cholesterol, mg/dl & 184 (158 to 203) & 185 (158 to 207) & $172(157$ to 201$)$ & 0.910 \\
\hline Triglycerides, mg/dl & 108 (84 to 137$)$ & 109 (84 to 149$)$ & $101(81$ to 131$)$ & 0.604 \\
\hline High-density lipoprotein cholesterol, mg/dl & 52 (42 to 63$)$ & $52(42$ to 69$)$ & 51 (47 to 59$)$ & 0.947 \\
\hline Low-density lipoprotein cholesterol, mg/dl & 96 (80 to 125$)$ & 95 (80 to 125$)$ & 98 (78 to 125$)$ & 0.851 \\
\hline Erythrocyte sedimentation rate, $\mathrm{mm} / \mathrm{hr}$ & $8(5$ to 13$)$ & $8(4$ to 10$)$ & 12 (5 to 18$)$ & 0.097 \\
\hline High-sensitivity C-reactive protein, $\mathrm{g} / \mathrm{dl}$ & 1.7 (0.7 to 4.2$)$ & $1.2(0.7$ to 3.1$)$ & 3.0 (0.8 to 8$)$ & 0.221 \\
\hline
\end{tabular}

${ }^{a} \mathrm{ASAS}$, Assessment of SpondyloArthritis international Society; DMARD, Disease-modifying antirheumatic drug; IQR, Interquartile range; NSAID, Nonsteroidal anti-inflammatory drug; PASI, Psoriasis Area and Severity Index; PsA, Psoriatic arthritis; Pso, Psoriasis. Data are reported as median (IQR) unless indicated otherwise. DMARD therapy denotes methotrexate use, except for 1 patient who was taking both methotrexate and hydroxychloroquine. Biologic therapy indicates active TNF antagonist or anti-IL-12/23 receptor use except for one patient who was treated with abatacept for psoriatic arthritis. Reported $P$-values are for comparisons of Pso vs. PsA using Fisher's exact tests for categorical variables, Mann-Whitney U tests for non-normally distributed continuous variables, and Student's t-tests for normally distributed continuous variables. $P<0.05$ was set as the significance level. 
Table 2 Vascular inflammation is increased in patients with sacroiliitis $^{a}$

\begin{tabular}{|c|c|c|c|}
\hline & Pso $(n=38)$ & PsA $(n=27)$ & \\
\hline & Mean \pm SD & Mean \pm SD & $P$-value \\
\hline \multirow[t]{3}{*}{ Aortic SUV $\max$} & $6.46 \pm 1.43$ & $6.72 \pm 1.92$ & 0.536 \\
\hline & $\begin{array}{l}\text { Sacroiliitis absent } \\
\quad(n=53)\end{array}$ & $\begin{array}{l}\text { Sacroiliitis present } \\
\quad(n=12)\end{array}$ & \\
\hline & Mean \pm SD & Mean \pm SD & $P$-value \\
\hline Aortic SUV $\max$ & $6.39 \pm 1.49$ & $7.33 \pm 2.09$ & 0.038 \\
\hline
\end{tabular}

(Additional file 2: Table S2). When these analyses were performed using $\mathrm{SUV}_{\text {mean }}$ as the outcome variable, similar results were obtained. The aortic $\mathrm{SUV}_{\max }$ data are reported, as this measurement indicates the region of most intense vascular inflammation.

In multivariate regression analyses (Table 3), sacroiliitis remained highly associated with vascular inflammation, even after adjusting for age, sex and BMI $(\beta=$ $0.268, P<0.001)$ and with additional adjustment for hypertension, dyslipidemia, diabetes and tobacco use $(\beta=$ $0.270, P<0.001)$. PsA was also associated with vascular inflammation (Table 3 ) in both partially adjusted (age, sex and BMI; $\beta=0.117, P<0.001$ ) and fully adjusted models (age, sex, BMI, hypertension, dyslipidemia, diabetes and tobacco; $\beta=0.124, P<0.001$ ). To obtain a crude estimate for systemic inflammatory burden, multivariate regression analyses were further adjusted for ESR and hsCRP levels. Addition of ESR $(\beta=0.268, P<0.001)$ or hsCRP $(\beta=$ $0.303, P<0.001)$ as independent variables did not affect the relationship between sacroiliitis and vascular inflammation in fully adjusted models (Additional file 3: Table S3). PsA and aortic $S_{U} V_{\max }$ also remained significantly related after adding ESR $(\beta=0.110, P<0.001)$ or hsCRP $(\beta=0.133, P<0.001)$ into fully adjusted models. The

Table 3 Sacroiliitis and psoriatic arthritis are positively related to vascular inflammation even after adjustment for CVD risk factors ${ }^{a}$

\begin{tabular}{lcc}
\hline Regression factors & Age, sex and BMI & $\begin{array}{c}\text { Age, sex, BMI, HTN, } \\
\text { DL, DM, Tob }\end{array}$ \\
\hline Sacroiliitis & $0.268(P<0.001)$ & $0.270(P<0.001)$ \\
Psoriatic arthritis & $0.117(P<0.001)$ & $0.124(P<0.001)$
\end{tabular}

${ }^{a}$ Multivariate linear regression analyses were performed using aortic maximum standardized uptake $\left(\mathrm{SUV}_{\max }\right)$ as the dependent variable. Independent variables included in the model were (1) age, sex, body mass index (BMI) and either sacroiliitis (row 1, left column) or psoriatic arthritis (row 2, left column) or (2) age, sex, BMI, hypertension (HTN), dyslipidemia (DL), diabetes mellitus (DM), tobacco use (Tob) and either sacroiliitis (row 1, right column) or psoriatic arthritis (row 2 , right column). $\beta$-coefficients ( $P$-values) are reported for the effects of sacroiliitis or psoriatic arthritis on vascular inflammation (aortic SUV $V_{\max }$ ) after adjustment for cardiovascular disease risk factors (age, sex, BMI, HTN, DL, DM and Tob). $P$-values $<0.05$ were considered significant. contribution of sacroiliitis to aortic $\mathrm{SUV}_{\max }$ estimation beyond PsA and/or traditional CVD risk factors was determined using likelihood-ratio testing (Table 4). Sacroiliitis defined by CT scan predicted vascular inflammation (Table 4) above and beyond PsA in unadjusted models $\left(\chi^{2}=374.6, P<0.001\right)$ and beyond PsA and CVD risk factors in partially adjusted $\left(\chi^{2}=132.8, P<0.001\right)$ and fully adjusted models $\left(\chi^{2}=124.6, P<0.001\right)$. Together, these findings suggest that sacroiliitis defined by CT scan may independently confer risk of higher vascular inflammation in patients with Pso and PsA.

\section{Discussion}

To our knowledge, this report is the first to link sacroiliitis defined by CT scan and vascular inflammation in Pso and PsA, an association that persisted after adjustment for traditional CVD risk factors. Aortic inflammation measured by FDG-PET/CT was found to be greater in patients with evidence of sacroiliitis compared to those without SI joint disease. We were able to determine that sacroiliitis impacted vascular inflammation in a dose-dependent fashion, as aortic $\mathrm{SUV}_{\max }$ values were greatest in those with sacroiliitis definitively diagnosed by CT scan compared to those with no disease or suspected disease. Further, vascular inflammation measured by FDG-PET/CT correlated with sacroiliitis in both unadjusted models and in models adjusted for CVD risk factors and markers of systemic inflammation. Importantly, sacroiliitis was a strong predictor of CVD above and beyond PsA and traditional risk factors. Taken together, these findings suggest that sacroiliitis not only may identify those at risk for more severe joint disease $[28,29]$ but may also be an indicator of increased susceptibility to CVD.

Identification of sacroiliitis as a correlate of CVD holds tremendous clinical promise since it is a characteristic feature of PsA $[17,18]$ and can readily be screened for in this disorder. Since use of FDG-PET/CT for CVD risk stratification in Pso and PsA is unlikely to extend beyond the research realm in the foreseeable future,

Table 4 Sacroiliitis predicts vascular inflammation beyond psoriatic arthritis and CVD risk factors ${ }^{a}$

\begin{tabular}{lc}
\hline Model & Aortic SUV \\
\hline Unax & $\boldsymbol{X}^{2}(\boldsymbol{P}$-value $)$ \\
Partially adjusted & $374.6(<0.001)$ \\
Fully adjusted & $132.8(<0.001)$ \\
\hline
\end{tabular}

aikelihood ratio testing was applied in nested Tobit models to assess the incremental value of sacroiliitis in predicting aortic vascular inflammation. The outcome variable was aortic maximum standardized uptake $\left(S U V_{\text {max }}\right)$. Independent variables in the different models were as follows: psoriatic arthritis (unadjusted); age, sex, BMI and psoriatic arthritis (partially adjusted); and age, sex, BMI, hypertension, dyslipidemia, diabetes, tobacco use and psoriatic arthritis (fully adjusted). $X^{2}$ values are reported for each model. $P$-values $<0.05$ were considered significant. 
sacroiliitis could potentially serve as a marker of increased risk of CVD in these populations. Future studies should extend our findings by examining the relationship between sacroiliitis and CVD in other spondyloarthropathies, and by determining whether active inflammation in the SI joint confers even greater risk for CVD. Whether sacroiliitis also relates to other psoriatic comorbidities is a subject of ongoing investigation in our cohort.

It has been suggested that higher inflammatory burden imparts increased CVD risk in the systemic inflammatory diseases [4]. Indeed, greater skin disease severity has been linked to increased CVD mortality in Pso $[1,30,31,42]$, and this observation has been further supported by data demonstrating cardiometabolic and CVD modulation in lesional psoriatic skin $[43,44]$. Furthermore, PsA has generally been considered to represent a heightened inflammatory state compared to Pso alone [3], and thus PsA may confer an elevated risk of CVDassociated morbidity and mortality [45]. Although epidemiologic studies have yielded conflicting data regarding all-cause mortality risk in PsA [42,46-51], the results of several studies demonstrate that PsA increases CVDattributable mortality compared to the general population [30,42,52] and to Pso patients [32,33,42,53]. Our findings suggest that screening for particular features of Pso and PsA rather than global measures of systemic inflammation may be a more viable strategy for identifying patients at increased risk for CVD. In support of this notion, our results presented here demonstrate that sacroiliitis, as defined by CT scan, and vascular inflammation were associated with PsA above and beyond traditional CVD risk factors and independent of levels of systemic inflammatory markers (ESR and hsCRP). Thus, sacroiliitis may be a potentially useful metric of CVD beyond crude measures of systemic inflammation.

We acknowledge that this study has certain limitations and that additional research is required to corroborate and extend our findings. The modest sample size and single-center study design could affect the generalizability of the results. Further, FDG-PET/CT may not be suitable for widespread adoption, owing to its limited availability for nonmalignant conditions and its mild radiation exposure. In addition, evaluation of sacroiliitis by CT scan may overestimate the frequency of patients with sacroiliitis [41,54], which could have impacted our results. Although analyses were adjusted for CVD risk factors and markers of systemic inflammation, other potential confounding variables, including Pso and PsA disease duration as well as disease activity and therapy, may have decreased the magnitude of the observed associations. Our study design was generally inclusive in order to allow us to understand the impact of Pso and PsA on vascular inflammation across a wide range of disease manifestations and therapies (that is, in a setting closer to the "real world"). Thus, the relationship between sacroiliitis and vascular inflammation may have been underestimated, as no washout medication period was required prior to study enrollment. However, it is remarkable that, though many of the Pso and PsA patients were undergoing treatment to mitigate their inflammatory disease and/or CVD risk factors, we found that sacroiliitis and vascular inflammation were still readily detectible.

Despite these limitations, our data implicate sacroiliitis as a significant and novel marker of increased CVD risk in PsA. Further, FDG-PET/CT may hold promise to improve CVD risk estimation as well as to delineate tissue inflammation in the rheumatic diseases. The PACI study (ClinicalTrials.gov Identifier: NCT01778569) is uniquely poised to address these questions, as it includes a large, ongoing, longitudinal cohort in which serial FDG-PET/ CT scans will be utilized to detect incident sacroiliitis and CVD in Pso and PsA patients. Additional studies are needed to substantiate and expand our present findings, to link them to clinical prognoses and to understand the effects of treatment on tissue-specific inflammation in Pso and PsA patients.

\section{Conclusion}

Sacroiliitis is associated with increased vascular inflammation beyond traditional CVD risk factors, suggesting that sacroiliitis may identify patients at greater risk for vascular complications.

\section{Additional files}

Additional file 1: Table S1. Aortic vascular inflammation is greater in patients with the highest grade sacroiliitis. These data demonstrate that those patients with definitive sacroiliitis on $\mathrm{CT}$ scan demonstrate greater vascular inflammation by FDG-PET/CT compared to patients with suspected or no sacroiliac disease.

Additional file 2: Table S2. Correlation analysis of aortic vascular inflammation with clinical measures by subgroup. These data demonstrate that cardiovascular risk factors, sacroiliitis by CT scan and psoriatic arthritis are independently associated with vascular inflammation by FDG-PET/CT.

Additional file 3: Table S3. Sacroiliitis and psoriatic arthritis are positively related to vascular inflammation even after adjustment for cardiovascular disease risk factors and the markers of systemic inflammation ESR and CRP. These data demonstrate that sacroiliitis by CT scan and psoriatic arthritis are associated with vascular inflammation by FDG-PET/CT beyond traditional cardiovascular risk factors and circulating markers of systemic inflammation.

\section{Abbreviations}

CVD: Cardiovascular disease; DBP: Diastolic blood pressure; DMARD: Disease-modifying antirheumatic drug; ESR: Erythrocyte sedimentation rate; FDG-PET/CT: 18-Fluorodeoxyglucose-positron emission tomography/computed tomography; HDL: High-density lipoprotein; hsCRP: High-sensitivity C-reactive protein; LDL: Low-density lipoprotein; PASI: Psoriasis Area and Severity Index; PsA: Psoriatic arthritis; Pso: Psoriasis; ROI: Region of interest; SBP: Systolic blood pressure; SI: Sacroiliac; SUV: Standardized uptake value.

\section{Competing interests}

The authors declare that they have no competing interests. 


\section{Authors' contributions}

SR and NNM conceived of and designed the study. SR, JD, CM, HN, ELS and NNM acquired, analyzed and interpreted the data. SR, JD, CM, HN, ELS NNM were involved with the drafting and revision of the manuscript. All authors are accountable for the accuracy and integrity of the work, and all authors read and approved the final manuscript.

\section{Authors' information}

$\mathrm{SR}$ is an American Board of Internal Medicine-certified rheumatologist, a member of the Group for the Assessment of Psoriasis and Psoriatic Arthritis (GRAPPA) and a Metzger Clinical Scholar at the National Institutes of Health. SR has extensive expertise in the clinical, basic and translational mechanisms linking inflammatory disorders to cardiovascular and metabolic disease. JD is an Intramural Research Training Awardee (IRTA) at the National Institutes of Health who specializes in multimodal imaging analyses. CM is an American Board of Radiology-certified radiologist and nuclear medicine specialist who works at the National Institutes of Health Clinical Center. HN is an American Board of Dermatology-certified dermatologist with extensive expertise in psoriasis, graft-versus-host disease and the neutrophilic dermatoses, as well as a senior clinical scholar at the National Cancer Institute. ELS is an American Board of Internal Medicine-certified rheumatologist who practices at the Arthritis and Rheumatism Associates, which is the largest rheumatology practice in the Washington, DC, Virginia and Maryland area. He is also a member of the Group for the Assessment of Psoriasis and Psoriatic Arthritis (GRAPPA). NNM is an American Board of Internal Medicine-certified cardiologist who specializes in preventative cardiology and cardiovascular imaging. He is the inaugural Lasker Clinical Scholar and section chief in the Section of Inflammation and Cardiometabolic Diseases at the National Heart, Lung, and Blood Institute, National Institutes of Health. He is also a member of Group for the Assessment of Psoriasis and Psoriatic Arthritis (GRAPPA) and the founder of the Psoriasis, Atherosclerosis, and Cardiometabolic Disease Initiative (ClinicalTrials.gov Identifier: NCT01778569).

\section{Acknowledgements}

The authors would like to thank Daniel Shin for helpful discussions regarding statistical methodologies described in the manuscript and Robert Colbert for critical appraisal of the manuscript. This work was supported by intramural funding from the National Institutes of Health Clinical Center, the National Heart, Lung, and Blood Institute (NHLBI) and the National Institute of Arthritis and Musculoskeletal and Skin Diseases (NIAMS).

\section{Author details}

'Section of Inflammation and Cardiometabolic Diseases, National Heart, Lung, and Blood Institute (NHLBI), National Institutes of Health, Bethesda, MD 20892, USA. ${ }^{2}$ National Institute of Arthritis and Musculoskeletal and Skin Diseases (NIAMS), National Institutes of Health, Bethesda, MD 20892, USA. ${ }^{3}$ Nuclear Medicine Positron Emission Tomography Department, National Institutes of Health Clinical Center, Bethesda, MD 20892, USA. ${ }^{4}$ National Cancer Institute (NCl), National Institutes of Health, Bethesda, MD 20892, USA. ${ }^{5}$ Arthritis and Rheumatism Associate, Rockville, MD 20850, USA.

Received: 9 March 2014 Accepted: 17 July 2014

Published: 30 July 2014

\section{References}

1. Gelfand JM, Neimann AL, Shin DB, Wang X, Margolis DJ, Troxel AB: Risk of myocardial infarction in patients with psoriasis. JAMA 2006, 296:1735-1741.

2. Prodanovich S, Kirsner RS, Kravetz JD, Ma F, Martinez L, Federman DG: Association of psoriasis with coronary artery, cerebrovascular, and peripheral vascular diseases and mortality. Arch Dermatol 2009, 145:700-703.

3. Tobin AM, Veale DJ, Fitzgerald O, Rogers S, Collins P, O'Shea D, Kirby B: Cardiovascular disease and risk factors in patients with psoriasis and psoriatic arthritis. J Rheumatol 2010, 37:1386-1394.

4. Roman MJ, Salmon JE: Cardiovascular manifestations of rheumatologic diseases. Circulation 2007, 116:2346-2355.

5. Bural GG, Torigian DA, Chamroonrat W, Houseni M, Chen W, Basu S, Kumar $R$, Alavi A: FDG-PET is an effective imaging modality to detect and quantify age-related atherosclerosis in large arteries. Eur J Nucl Med Mol Imaging 2008, 35:562-569.

6. Mehta NN, Torigian DA, Gelfand JM, Saboury B, Alavi A: Quantification of atherosclerotic plaque activity and vascular inflammation using [18-F] fluorodeoxyglucose positron emission tomography/computed tomography (FDG-PET/CT). J Vis Exp 2012, 63:e3777.

7. Rudd JHF, Warburton EA, Fryer TD, Jones HA, Clark JC, Antoun N, Johnström P, Davenport AP, Kirkpatrick PJ, Arch BN, Pickard JD, Weissberg PL: Imaging atherosclerotic plaque inflammation with $\left[{ }^{18} \mathrm{~F}\right]$-fluorodeoxyglucose positron emission tomography. Circulation 2002, 105:2708-2711.

8. Tahara N, Kai H, Nakaura H, Mizoguchi M, Ishibashi M, Kaida H, Baba K, Hayabuchi N, Imaizumi T: The prevalence of inflammation in carotid atherosclerosis: analysis with fluorodeoxyglucose-positron emission tomography. Eur Heart J 2007, 28:2243-2248.

9. Tawakol A, Migrino RQ, Hoffmann U, Abbara S, Houser S, Gewirtz H, Muller $\mathrm{JE}$, Brady TJ, Fischman AJ: Noninvasive in vivo measurement of vascular inflammation with F-18 fluorodeoxyglucose positron emission tomography. J Nucl Cardiol 2005, 12:294-301.

10. Abdelbaky A, Corsini E, Figueroa AL, Fontanez S, Subramanian S, Ferencik M, Brady TJ, Hoffmann U, Tawakol A: Focal arterial inflammation precedes subsequent calcification in the same location: a longitudinal FDG-PET/CT study. Circ Cardiovasc Imaging 2013, 6:747-754.

11. Paulmier B, Duet M, Khayat R, Pierquet-Ghazzar N, Laissy JP, Maunoury C, Hugonnet F, Sauvaget E, Trinquart L, Faraggi M: Arterial wall uptake of fluorodeoxyglucose on PET imaging in stable cancer disease patients indicates higher risk for cardiovascular events. J Nucl Cardiol 2008, 15:209-217.

12. Rominger A, Saam T, Wolpers S, Cyran CC, Schmidt M, Foerster S, Nikolaou K, Reiser MF, Bartenstein P, Hacker M: 18 F-FDG PET/CT identifies patients at risk for future vascular events in an otherwise asymptomatic cohort with neoplastic disease. J Nucl Med 2009, 50:1611-1620.

13. Mehta NN, Yu Y, Saboury B, Foroughi N, Krishnamoorthy P, Raper A, Baer A, Antigua J, Van Voorhees AS, Torigian DA, Alavi A, Gelfand JM: Systemic and vascular inflammation in patients with moderate to severe psoriasis as measured by [18 F]-fluorodeoxyglucose positron emission tomographycomputed tomography (FDG-PET/CT): a pilot study. Arch Dermatol 2011, 147:1031-1039.

14. Rose S, Sheth NH, Baker JF, Ogdie A, Raper A, Saboury B, Werner TJ, Thomas P, Vanvoorhees A, Alavi A, Torigian DA, Gelfand JM, Mehta NN: A comparison of vascular inflammation in psoriasis, rheumatoid arthritis, and healthy subjects by FDG-PET/CT: a pilot study. Am J CardiovasC Dis 2013, 3:273-278.

15. Yu Y, Sheth N, Krishnamoorthy P, Saboury B, Raper A, Baer A, Ochotony R, Doveikis J, Derohannessian S, Voorhees AS, Torigian DA, Alavi A, Gelfand JM, Mehta NN: Aortic vascular inflammation in psoriasis is associated with HDL particle size and concentration: a pilot study. Am J Cardiovasc Dis 2012, 2:285-292.

16. Helliwell PS: Relationship of psoriatic arthritis with the other spondyloarthropathies. Curr Opin Rheumatol 2004, 16:344-349.

17. Rudwaleit M, Taylor WJ: Classification criteria for psoriatic arthritis and ankylosing spondylitis/axial spondyloarthritis. Best Pract Res Clin Rheumatol 2010, 24:589-604.

18. Rudwaleit M, van der Heijde $D$, Landewé R, Akkoc N, Brandt J, Chou CT, Dougados M, Huang F, Gu J, Kirazli Y, Van den Bosch F, Olivieri I, Roussou E, Scarpato S, Sørensen IJ, Valle-Oñate R, Weber U, Wei J, Sieper J: The Assessment of SpondyloArthritis International Society classification criteria for peripheral spondyloarthritis and for spondyloarthritis in general. Ann Rheum Dis 2011, 70:25-31.

19. Cammisa M, Lomuto M, Bonetti MG: Sacroiliitis in seronegative polyarthritis: CT analysis. Clin Exp Rheumatol 1987, 5:S105-S107.

20. Devauchelle-Pensec V, D'Agostino MA, Marion J, Lapierre M, Jousse-Joulin S, Colin D, Chary-Valckenaere I, Marcelli C, Loeuille D, Aegerter P, Guis S, Gaudin P, Breban M, Saraux A, Study Group of Spondylarthritis: Computed tomography scanning facilitates the diagnosis of sacroiliitis in patients with suspected spondylarthritis: results of a prospective multicenter French cohort study. Arthritis Rheum 2012, 64:1412-1419.

21. Fewins HE, Whitehouse GH, Bucknall RC: Role of computed tomography in the evaluation of suspected sacroiliac joint disease. J R Soc Med 1990, 83:430-432

22. Kozin F, Carrera GF, Ryan LM, Foley D, Lawson T: Computed tomography in the diagnosis of sacroiliitis. Arthritis Rheum 1981, 24:1479-1485.

23. Lawson TL, Foley WD, Carrera GF, Berland LL: The sacroiliac joints: anatomic, plain roentgenographic, and computed tomographic analysis. J Comput Assist Tomogr 1982, 6:307-314.

24. Lee YH, Hwang JY, Lee SW, Lee J: The clinical usefulness of multidetector computed tomography of the sacroiliac joint for evaluating spondyloarthropathies. Korean J Intern Med 2007, 22:171-177. 
25. Puhakka KB, Jurik AG, Egund N, Schiottz-Christensen B, StengaardPedersen K, van Overeem Hansen G, Christiansen JV: Imaging of sacroiliitis in early seronegative spondylarthropathy: assessment of abnormalities by MR in comparison with radiography and CT. Acta Radiol 2003, 44:218-229.

26. Strobel K, Fischer DR, Tamborrini G, Kyburz D, Stumpe KD, Hesselmann RG Johayem A, von Schulthess GK, Michel BA, Ciurea A: ${ }^{18}$ F-fluoride PET/CT for detection of sacroiliitis in ankylosing spondylitis. Eur J NuCl Med Mol Imaging 2010, 37:1760-1765.

27. Geijer M, Sihlbom H, Göthlin JH, Nordborg E: The role of CT in the diagnosis of sacro-iliitis. Acta Radiol 1998, 39:265-268.

28. Chandran V, Tolusso DC, Cook RJ, Gladman DD: Risk factors for axial inflammatory arthritis in patients with psoriatic arthritis. J Rheumatol 2010, 37:809-815.

29. Taccari E, Spadaro A, Riccieri V: Correlations between peripheral and axia radiological changes in patients with psoriatic polyarthritis. Rev Rhum Engl Ed 1996, 63:17-23.

30. Gladman DD, Ang M, Su L, Tom BD, Schentag CT, Farewell VT: Cardiovascular morbidity in psoriatic arthritis. Ann Rheum Dis 2009, 68:1131-1135.

31. Mehta NN, Yu Y, Pinnelas R, Krishnamoorthy P, Shin DB, Troxel AB, Gelfand $\mathrm{JM}$ : Attributable risk estimate of severe psoriasis on major cardiovascular events. Am J Med 2011, 124:775. e1-775.e6.

32. Husted JA, Thavaneswaran A, Chandran V, Eder L, Rosen CF, Cook RJ, Gladman DD: Cardiovascular and other comorbidities in patients with psoriatic arthritis: a comparison with patients with psoriasis. Arthritis Care Res (Hoboken) 2011, 63:1729-1735.

33. Miller IM, Ellervik C, Yazdanyar S, Jemec GB: Meta-analysis of psoriasis, cardiovascular disease, and associated risk factors. J Am Acad Dermatol 2013, 69:1014-1024.

34. National Institutes of Health, PACl: The Psoriasis, Atherosclerosis, and Cardiometabolic Disease Initiative. [http://psoriasis.nhlbi.nih.gov] (accessed 7 August 2014)

35. ResearchMatch. [https://www.researchmatch.org] (accessed 7 August 2014).

36. Taylor W, Gladman D, Helliwell P, Marchesoni A, Mease P, Mielants H: Classification criteria for psoriatic arthritis: development of new criteria from a large international study. Arthritis Rheum 2006, 54:2665-2673.

37. Felson DT, Anderson JJ, Boers M, Bombardier C, Chernoff M, Fried B, Furst D, Goldsmith C, Kieszak S, Lightfoot R Jr, Paulus H, Tugwell P, Weinblatt M, Wildmark R, Williams HJ, Wolfe F, the Committee on Outcome Measures in Rheumatoid Arthritis Clinical Trials: The American College of Rheumatology preliminary core set of disease activity measures for rheumatoid arthritis clinical trials. Arthritis Rheum 1993, 36:729-740

38. Healy PJ, Helliwell PS: Measuring clinical enthesitis in psoriatic arthritis: assessment of existing measures and development of an instrument specific to psoriatic arthritis. Arthritis Rheum 2008, 59:686-691.

39. Sieper J, van der Heijde D, Landewé R, Brandt J, Burgos-Vagas R, CollantesEstevez E, Dijkmans B, Dougados M, Khan MA, Leirisalo-Repo M, van der Linden S, Maksymowych WP, Mielants H, Olivieri I, Rudwaleit M: New criteria for inflammatory back pain in patients with chronic back pain: a real patient exercise by experts from the Assessment of SpondyloArthritis international Society (ASAS). Ann Rheum Dis 2009, 68:784-788

40. Calin A, Porta J, Fries JF, Schurman DJ: Clinical history as a screening test for ankylosing spondylitis. JAMA 1977, 237:2613-2614

41. Geijer M, Gadeholt Gothlin G, Gothlin JH: The validity of the New York radiological grading criteria in diagnosing sacroiliitis by computed tomography. Acta Radiol 2009, 50:664-673.

42. Ahlehoff $\mathrm{O}$, Gislason $\mathrm{GH}$, Charlot M, Jørgensen $\mathrm{CH}$, Lindhardsen J, Olesen JB, Abildstrøm SZ, Skov L, Torp-Pedersen C, Hansen PR: Psoriasis is associated with clinically significant cardiovascular risk: a Danish nationwide cohort study. J Intern Med 2011, 270:147-157.

43. Mehta NN, Li K, Szapary P, Krueger J, Brodmerkel C: Modulation of cardiometabolic pathways in skin and serum from patients with psoriasis. J Transl 'aMed 2013, 11:194.

44. Suárez-Fariñas M, Li K, Fuentes-Duculan J, Hayden K, Brodmerkel C, Krueger JG: Expanding the psoriasis disease profile: interrogation of the skin and serum of patients with moderate-to-severe psoriasis. J Invest Dermatol 2012, 132:2552-2564.

45. Jamnitski A, Symmons D, Peters MJ, Sattar N, Mclnnes I, Nurmohamed MT: Cardiovascular comorbidities in patients with psoriatic arthritis: a systematic review. Ann Rheum Dis 2013, 72:211-216.
46. Ali Y, Tom BD, Schentag CT, Farewell VT, Gladman DD: Improved survival in psoriatic arthritis with calendar time. Arthritis Rheum 2007, 56:2708-2714.

47. Buckley C, Cavill C, Taylor G, Kay H, Waldron N, Korendowych E, McHugh N: Mortality in psoriatic arthritis: a single-center study from the UK. J Rheumatol 2010, 37:2141-2144.

48. Gladman DD, Farewell VT, Wong K, Husted J: Mortality studies in psoriatic arthritis: results from a single outpatient center. II. Prognostic indicators for death. Arthritis Rheum 1998, 41:1103-1110.

49. Ogdie A, Haynes K, Troxel AB, Love TJ, Hennessy S, Choi H, Gelfand JM: Risk of mortality in patients with psoriatic arthritis, rheumatoid arthritis and psoriasis: a longitudinal cohort study. Ann Rheum Dis 2014, 73:149-153.

50. Shbeeb M, Uramoto KM, Gibson LE, O'Fallon WM, Gabriel SE: The epidemiology of psoriatic arthritis in Olmsted County, Minnesota, USA, 1982-1991. J Rheumatol 2000, 27:1247-1250.

51. Wong K, Gladman DD, Husted J, Long JA, Farewell VT: Mortality studies in psoriatic arthritis: results from a single outpatient clinic. I Causes and risk of death. Arthritis Rheum 1997, 40:1868-1872.

52. Han C, Robinson DW Jr, Hackett MV, Paramore LC, Fraeman KH, Bala MV: Cardiovascular disease and risk factors in patients with rheumatoid arthritis, psoriatic arthritis, and ankylosing spondylitis. J Rheumatol 2006, 33:2167-2172.

53. Chin YY, Yu HS, Li WC, Ko YC, Chen GS, Wu CS, Lu YW, Yang YH, Lan CC: Arthritis as an important determinant for psoriatic patients to develop severe vascular events in Taiwan: a nation-wide study. J Eur Acad Dermatol Venereol 2013, 27:1262-1268.

54. Slobodin G, Croitoru S, Starikov N, Younis S, Boulman N, Rimar D, Rosner I, Rozenbaum M, Odeh M: Incidental computed tomography sacroiliitis: clinical significance and inappropriateness of the New York radiological grading criteria for the diagnosis. Clin Rheumatol 2012, 31:425-428.

\section{doi:10.1186/ar4676}

Cite this article as: Rose et al.: Psoriatic arthritis and sacroiliitis are associated with increased vascular inflammation by

18-fluorodeoxyglucose positron emission tomography computed tomography: baseline report from the Psoriasis Atherosclerosis and Cardiometabolic Disease Initiative. Arthritis Research \& Therapy 2014 16:R161.

\section{Submit your next manuscript to BioMed Central and take full advantage of:}

- Convenient online submission

- Thorough peer review

- No space constraints or color figure charges

- Immediate publication on acceptance

- Inclusion in PubMed, CAS, Scopus and Google Scholar

- Research which is freely available for redistribution 